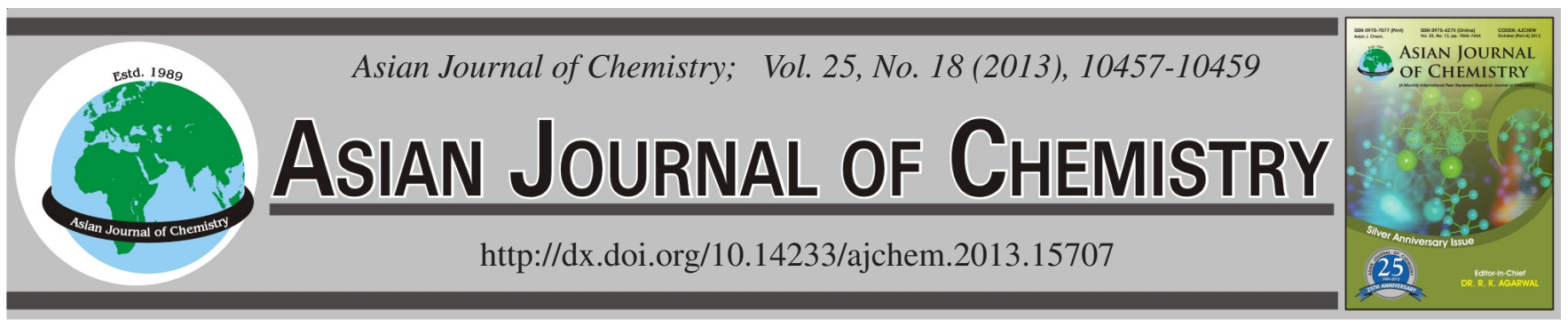

\title{
Spectrophotometric Determination of Trace Zinc in Yeast by Using 2-(5-Bromo-2-pyridylazo)-5-diethylaminophenol
}

\author{
Xianzhong Cheng ${ }^{1, *}$, Yuan Peng ${ }^{1}$, Jing Shu $^{2}$, ShunXi Zhang ${ }^{1}$ and Guoqing Zhou ${ }^{1}$
}

${ }^{1}$ School of Chemical and Environmental Engineering, Wuhan Polytechnic University, Wuhan 430023, P.R. China

${ }^{2}$ College of Food Science and Engineering, Wuhan Polytechnic University, Wuhan 430023, P.R. China

*Corresponding author: Tel: +86 27 83943956; E-mail: whcxz502@163.com; xzcheng@whpu.edu.cn

\begin{abstract}
A simple and rapid spectrophotometric method is described for the determination of trace zinc(II) in zinc-enriched yeast using 2-(5bromo-2-pyridylazo)-5-diethylaminophenol (5-Br-PADAP) as a chromogenic reagent in the presence of surfactant OP. The analytical parameters such $\mathrm{pH}$, reagent and coexistent ions were investigated. The results showed that the maximum absorption wavelength of the complex Zn-5-Br-PADAP was identified at $556 \mathrm{~nm}$. The apparent molar absorptivity was $1.16 \times 10^{5} \mathrm{~L} \mathrm{~mol}^{-1} \mathrm{~cm}^{-1}$. Beer's law was obeyed in the concentration range of $0 \sim 12 \mu \mathrm{g} / 25 \mathrm{~mL}$ for zinc. The interference of various ions was studied by sodium citrate and thiourea as masking agents. The proposed method has been applied to the determination of $\mathrm{Zn}$ in yeast-enriched samples with satisfactory and results agreed with those provided by atomic absorption spectrometry.
\end{abstract}

Key Words: Spectrophotometric, 2-(5-Bromo-2-pyridylazo)-5-diethylaminophenol, Surfactant, Yeast, Zinc.

\section{INTRODUCTION}

Yeast is an unicellular eukaryotic microorganisms with abundant nutrition, which has been widely used in the food, beverage, medicine and wine-making industries ${ }^{1}$. Recently, zinc-rich yeast is also considered as potential applications to provide organism with indispensable and zinc micronutrient. Zinc is an essential element for many processes in the living organisms. It is one of the most important trace elements in the body for its biological functions, which is also recognized as a catalytic component for more than 300 enzymes and as a structure constituent of many proteins, neuropeptides, hormones, hormone receptors and polynucleotides ${ }^{2}$. The deficiency of zinc in an organism can cause serious consequences such as growth retardation, diarrhea, the decrease of the immunological defense, eye and skin lesions and other skin diseases ${ }^{3,4}$. Zinc is name "wisdom elements" and is of important physiological function, plays an important role in brain's growth and functional maturation. Thus, it is of vital meanings the determination of zinc in yeast.

At present, the method for determination of trace zinc has mainly derivative spectrophotometry ${ }^{5,6}$, atomic absorption spectrometry ${ }^{7,8}$, inductively coupled plasma atomic emission spectrometry ${ }^{9}$, inductively coupled plasma mass spectrometry ${ }^{10}$. Although these methods have excellent sensitivity, but these are costly and expensive and can suffer from serious matrix interference in routine analysis ${ }^{11}$. Compared with classical direct methods, spectrophotometry is most convenient, simple operation and comical to use.

2-(5-Bromo-2-pyridylazo)-5-diethylaminophenol (5-BrPADAP) is a sensitive chromospheres reagent and has been used as an analytical reagent in the spectrophotometric determination of many metallic ions ${ }^{12-14}$, in order to avoid the precipitation of the corresponding chelate, such as the addition of surfactant agent. In this paper, the microwaves digestion to deal with yeast sample and determines the trace zinc in yeast by combining with the 5-Br-PADAP spectrophotometric determination was studied. This method is simple and rapid, the analysis of which is satisfied and agreed with that provided by atomic absorption spectrometry.

\section{EXPERIMENTAL}

Absorption measurements were performed with a Unicam UV-510 UV-visible spectrophotometer (Thermo Spectronic, USA). A TBS-990 atomic absorption spectrophotometer (Beijing Purkinge General Instrument Co. Ltd., Beijing, China) was used for determination of zinc. The $\mathrm{pH}$ values of the solutions were measured with a $\mathrm{pH}$ meter (Thermo Orion Corporation, America) supplied with a combined Electrode. A MSD-2002A Closed-Vessel Microwave-Controlled Pressure System (Shanghai SINEO Microwave Chemistry Technology Co., Ltd, Shanghai, P.R. China) was used to digest yeast sample. 
The stock standard solution of $1000 \mathrm{mg} / \mathrm{mL} \mathrm{Zn} \mathrm{(II)} \mathrm{was}$ purchased from the National Research Centre for certified Reference Materials (Beijing, China). The working standard solutions were daily prepared by appropriate dilution with deionized water.

A solution of 5-Br-PADAP $\left(0.25 \mathrm{~g} \mathrm{~L}^{-1}\right)$ was prepared by dissolving $0.125 \mathrm{~g}$ of the regents in $500 \mathrm{~mL}$ of ethanol. The Emulsifier OP was prepared to $20 \%$ (v/v) water solution. A $\mathrm{pH} 8.7$ of buffer solution was prepared by dissolving with $27.2 \mathrm{~g} / \mathrm{L}$ sodium hydrogen-phosphate $(\mathrm{m} / \mathrm{v})$ and $38 \mathrm{~g} / \mathrm{L}$ sodium tetraborate in $1000 \mathrm{~mL}$ of deionized water.

All reagents were of analytical grade. Deionized water (DW) was used throughout.

General procedure: An aliquot of working standard solution containing 1-20 $\mu \mathrm{g}$ of $\mathrm{Zn}$ (II) was transferred into $25 \mathrm{~mL}$ volumetric flask. The $\mathrm{pH}$ of this solution was adjusted to $\mathrm{pH} 8$ with $0.1 \mathrm{~mol} / \mathrm{L} \mathrm{NH}_{3} \cdot \mathrm{H}_{2} \mathrm{O}$ or $\mathrm{HCl}$ solution. Then, $5 \mathrm{~mL}$ of $\mathrm{pH} 8.7$ buffer solution, $2 \mathrm{~mL} 20 \%$ emulsifier OP buffer solution, $0.8 \mathrm{~mL} 0.03 \%$ 5-Br-PADAP solution were added, respectively. It was allowed to stand for enough time for the appearance of an orange-red colour. The mixtures were diluted to the mark with deionized water and shaken thoroughly. The absorbance was measured at $556 \mathrm{~nm}$ against a corresponding reagent blank in a $1 \mathrm{~cm}$ quarter cell by spectrophotometer. The results of sample analysis were compared with the appropriate calibration graphs.

Sample preparation: $0.25 \mathrm{~g}$ of yeast sample (precision $0.1 \mathrm{mg}$ ) was accurately weighed in a microwave oven vessel, to which $4 \mathrm{~mL}$ of concentrated $\mathrm{HNO}_{3}$ and $2 \mathrm{~mL}$ of $\mathrm{H}_{2} \mathrm{O}_{2}(30 \%$, $\mathrm{m} / \mathrm{m}$ ) were added. The mixture was left standing for $0.5 \mathrm{~h}$ and then heated in microwave digestion system according to program listed in Table-1. Once cool, the obtained solutions were transferred to a $100 \mathrm{~mL}$ volumetric flask and diluted to the mark with deionized water. Then $5.0 \mathrm{~mL}$ of this solution was analyzed according to the given procedure for $25 \mathrm{~mL}$ and compared with the FAAS method. At the same time, absorption is measured and blank experiment done.

\begin{tabular}{|c|c|c|c|}
\hline & $\begin{array}{l}\text { PROGR } \\
\text { DIGESTI }\end{array}$ & $\begin{array}{l}\text { ABLE-1 } \\
\text { OR MICROWA } \\
\text { F YEAST SAMP }\end{array}$ & \\
\hline & Time $(\mathrm{min})$ & Pressure (MPa) & Temperature $\left({ }^{\circ} \mathrm{C}\right)$ \\
\hline Step 1 & 5 & 0.5 & 120 \\
\hline Step 2 & 2 & 1.0 & 200 \\
\hline Step 3 & 10 & 2.5 & 240 \\
\hline Step 4 & 20 & 0.2 & 100 \\
\hline \multicolumn{4}{|c|}{ RESULTS AND DISCUSSION } \\
\hline
\end{tabular}

Absorption spectra: In the butter solution with $\mathrm{pH}$ 8.7, zinc reacts with 5-Br-PADAP to form a red complex. The absorption spectra of the complex are shown in Fig. 1. It is evident that the maximum absorption peak is at $556 \mathrm{~nm}$. In order to achieve high sensitivity, a wavelength of $556 \mathrm{~nm}$ was chosen for the spectrophotometric measurement of zinc.

Choice of pH: The effect of the $\mathrm{pH}$ of 5-Br-PADAP complexes of zinc has been investigated. The reaction of zinc with 5-Br-PADAP can be carried out in the $\mathrm{pH}$ range 8.0-9.2, which would produces impacts both on the absorption stability of the complex and selectivity, sensitivity of the reaction. The

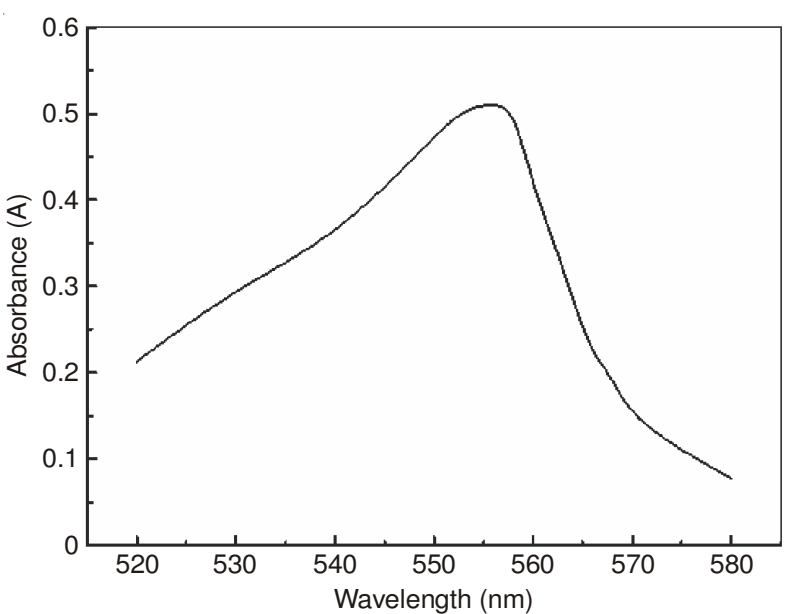

Fig. 1. Absorption spectrum

optimum $\mathrm{pH}$ for the formation and fixation of the complex fell in the range of 8.0-9.0 (Fig. 2). It was found that absorbance increased with increasing $\mathrm{pH}$ value up to 8.8 , above which the maximal absorption of the system remained constant over the range between 8.0 and 8.8 of the $\mathrm{pH}$ value. Outside this range the absorbance decreased. For all subsequent measurements, the $\mathrm{pH} 8.7$ was selected.

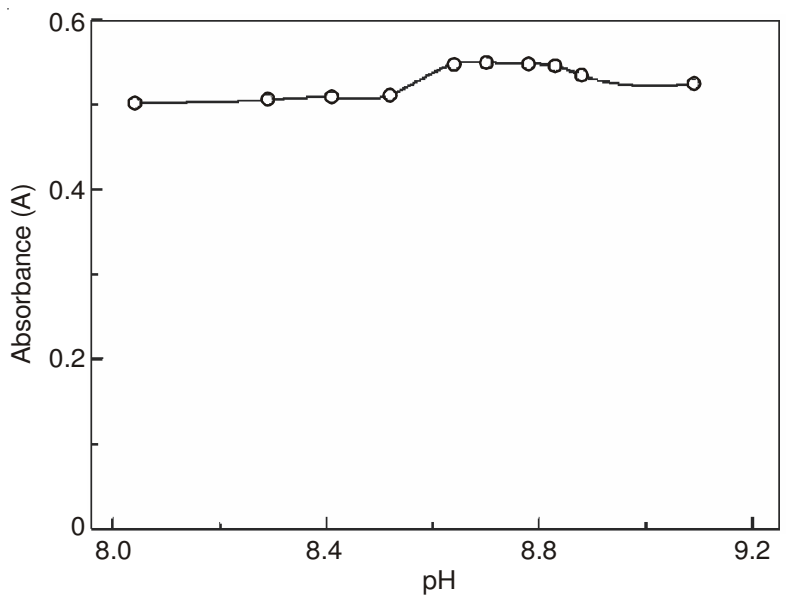

Fig. 2. Effect of $\mathrm{pH}$ on the absorbance

Effect of the amount of 5-Br-PADAP: The effect of the 5-Br-PADAP on the colour development of the zinc-5-BrPADAP complex was examined. With the increasing concentration of 5-Br-PADAP, the absorption of the complex begins to increase dramatically as shown in Fig. 3. Then, the absorption is constant and maximal between $0.5-1.0 \mathrm{~mL}$. Therefore, $0.8 \mathrm{~mL}$ of 5-Br-PADAP was adopted for further study.

Effect of the amount of emulsifier OP: As the solubilization of zinc-complex, emulsifier OP makes the complex stable in solution. According to the general procedure, the amounts of emulsifier OP were changed between 1-5 mL. The results indicate that the absorption was constant and maximal in the range of 2-3 $\mathrm{mL}$ for $20 \%$ emulsifier OP solution. Therefore, $2.5 \mathrm{~mL}$ of $20 \%$ emulsifier OP was chosen and the complex can be kept in stabilization for $8 \mathrm{~h}$ in the presence of surfactant.

Effect of coexist ions: In order to evaluate the selectivity of the proposed method, the interference from foreign ions in the determination of zinc(II) by the method proposed has been 


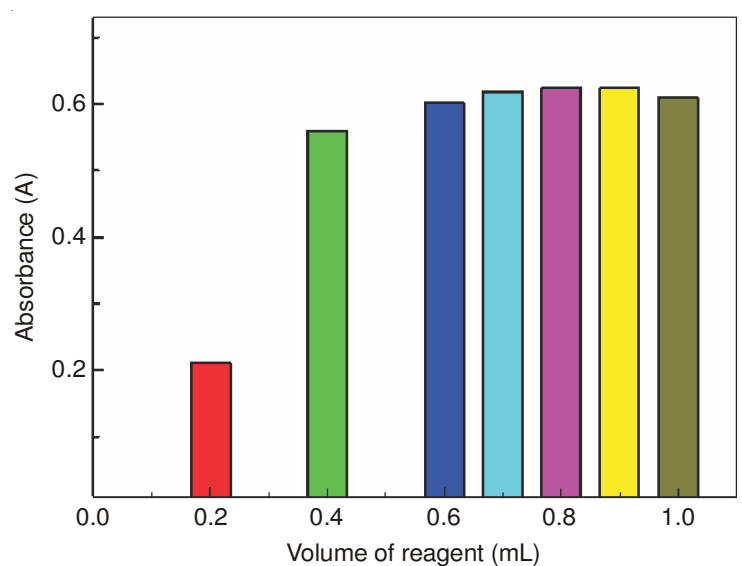

Fig. 3. Effect of the amount of 5-Br-PADAP on the absorbance

studied with solution containing $5 \mu \mathrm{g}$ of $\mathrm{Zn}$. Various ions tolerated limits are measured within the absorption is $\pm 5 \%$ relative error: $\mathrm{K}^{+}, \mathrm{Na}^{+}, \mathrm{Ca}^{2+}, \mathrm{Mg}^{2+}, \mathrm{NH}_{4}^{+}, \mathrm{Cl}^{-}, \mathrm{SO}_{4}{ }^{2-}, \mathrm{F}^{-}, \mathrm{NO}_{3}^{-}$ $(2.0 \mathrm{mg}) ; \mathrm{Pb}^{2+}(100 \mu \mathrm{g}), \mathrm{Mn}^{2+}(100 \mu \mathrm{g}), \mathrm{Cr}(\mathrm{VI})(70 \mu \mathrm{g}), \mathrm{Fe}^{3+}(50$ $\mu \mathrm{g}), \mathrm{Cu}^{2+}(30 \mu \mathrm{g}), \mathrm{Ni}^{2+}(20 \mu \mathrm{g}), \mathrm{Co}^{2+}(10 \mu \mathrm{g}), \mathrm{Cd}^{2+}(10 \mu \mathrm{g})$; $\mathrm{As}(\mathrm{III})(200 \mu \mathrm{g}), \mathrm{Al}^{3+}(200 \mu \mathrm{g}), \mathrm{La}^{2+}(100 \mu \mathrm{g})$. The main components in yeast powder are organic compounds and containing $\mathrm{K}^{+}, \mathrm{Na}^{+}, \mathrm{Ca}^{2+}$ and $\mathrm{Mg}^{2+}$ while others are trace. Based on the above data, it was found that $\mathrm{Cu}(\mathrm{II}), \mathrm{Co}(\mathrm{II}), \mathrm{Ni}$ (II) and $\mathrm{Cd}(\mathrm{II})$ interfered severely even present in trace amounts (up to 2fold excess). But the interference of $\mathrm{Cu}$ (II) can be eliminated by adding $1 \mathrm{~mL}$ of $0.5 \%$ sodium citrate solution as masking agent. $\mathrm{Co}(\mathrm{II}), \mathrm{Ni}(\mathrm{II})$ and $\mathrm{Cd}(\mathrm{II})$ can be avoided by using $1 \mathrm{~mL}$ of $0.5 \%$ sodium thiosulfate.

Microwave digestion condition: Various acid solutions such as $\mathrm{HNO}_{3}, \mathrm{HNO}_{3}-\mathrm{H}_{2} \mathrm{O}_{2}, \mathrm{HCl}-\mathrm{HNO}_{3}$ and $\mathrm{HNO}_{3}-\mathrm{HClO}_{4}$ were tested to digested yeast sample. It was found that the $\mathrm{HNO}_{3}-\mathrm{H}_{2} \mathrm{O}_{2}(2: 1)$ system has the best effect of dissolving sample. A hydrogen peroxide is extremely beneficial to digest organic compound ${ }^{15}, 2.0 \mathrm{~mL}$ was added. Both of the pressure and temperature are most important parameters in the course of microwave digestion. Therefore, the inside pressure of vessel, microwave power and digestion time were examined. The yeast samples were subjected to the following digestion program: $5 \mathrm{~min}$ at $0.5 \mathrm{MPa}, 2 \mathrm{~min}$ at $1.0 \mathrm{MPa}, 10 \mathrm{~min}$ at $2.5 \mathrm{MPa}$ and $10 \mathrm{~min}$ at $0.2 \mathrm{MPa}$. The result shows that samples were digested completely with the apparent, without residue.

Analytical data: The calibration graphs were linear for the concentration ranges $0.05-1.0 \mu \mathrm{g} / \mathrm{mL} \mathrm{Zn}$ (II) for the $25 \mathrm{~mL}$ sample system. The calibration curve obtained and the linear regression equation $\mathrm{A}=0.05643 \mathrm{C}+0.00957$ in the concentration examined. The correlation coefficient $\mathrm{r}$ is 0.998 and complex's apparent molar absorption coefficient is $1.16 \times 10^{5}$ $\mathrm{L} \mathrm{mol}^{-1} \mathrm{~cm}^{-1}$.

Sample analysis: The proposed method was successfully applied to the determination of $\mathrm{Zn}$ in $\mathrm{Zn}$-rich yeast samples. The results obtained by the method were compared statistically with those of the FAAS method (Table-2). Both Student's $t$ test and $F$ value were used to do a significant difference test for proposed method and FAAS. There was no remarkable
TABLE-2

RESULTS OF ZINC IN YEAST SAMPLES AFTER APPLICATION OF PROPOSED AND FAAS METHOD $(n=5)$

\begin{tabular}{cccccc}
\hline Sample $^{\mathrm{a}}$ & $\begin{array}{c}\text { Conc. } \\
(\mu \mathrm{g} / \mathrm{g})\end{array}$ & $\begin{array}{c}\text { RSD } \\
(\%)\end{array}$ & t-Test & F-Value & $\begin{array}{c}\text { FAAS } \\
(\mu \mathrm{g} / \mathrm{g})\end{array}$ \\
\hline CY1332 & $189 \pm 0.9$ & 1.15 & 1.07 & 2.13 & $189 \pm 1.3$ \\
CY1338 & $290 \pm 1.1$ & 1.03 & 1.21 & 2.26 & $287 \pm 1.9$ \\
CY1245 & $253 \pm 0.8$ & 0.84 & 1.16 & 2.18 & $252 \pm 0.9$ \\
CY1155 & $312 \pm 2.3$ & 0.67 & 0.91 & 2.31 & $309 \pm 3.1$ \\
\hline
\end{tabular}

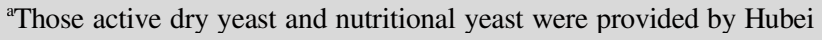
Angel Yeast stock company (China).

difference between the data obtained from the two methods $\left(\mathrm{t}=1.03, \mathrm{t}<\mathrm{t}_{0.10,9}\right)$. The proposed method, on the other hand, can be applied in routine analysis as an alternative to the FAAS method.

\section{Conclusion}

A simple spectrophotometric method was developed for the determination of zinc in zinc-rich yeast by using 5-BrPADAP as colorimetric reagent. The results for this work demonstrate the possibility of using the 5-Br-PADAP-OP system for the determination of zinc. The interferences were eliminated with sodium citrate and thiourea solution agents. The measurement results are satisfactory and agreed with those provided by atomic absorption spectrometry. Additionally, the microwave digestion makes it such a versatile method, being adequate for yeast biological studies.

\section{ACKNOWLEDGEMENTS}

This project was supported by the Hubei Provincial Natural Science Foundation of China (No. 2008CDA100) and the teacher scientific innovation program of Wuhan Polytechnic University (No. 2012Y27).

\section{REFERENCES}

1. Y. Koh, Mol. Neurobiol., 24, 99 (2001).

2. F. Rodríguez-Gómez, F.N. Arroyo-López, A. López-López, J. BautistaGallego and A. Garrido-Fernández, Food Microbiol., 27, 604 (2010).

3. M.J. Salgueiro, M. Zubillaga, A. Lysionek, M.I. Sarabia, R. Caro, T. De Paoli, A. Hager, R. Weill and J. Boccio, Nutr. Res., 20, 737 (2000).

4. J.M. Flinn, D. Hunter, D.H. Linkous, A. Lanzirotti, L.N. Smith, J. Brightwell and B.F. Jones, Physiol. Behav, 83, 793 (2005).

5. W. Thanasarakhan, S. Liawruangrath, S. Wangkarn and B. Liawruangrath, Talanta, 71, 1849 (2007)

6. H. Abdolmohammad-Zadeh and G.H. Sadeghi, Anal. Chim. Acta, 649, 211 (2009).

7. M.Y. Asci, A. Efendioglu and B. Bati, Asian J. Chem., 24, 2497 (2012).

8. J.L. Gu and G. Zhao, Asian J. Chem., 25, 4356 (2013).

9. E. Tusat, M. Mu. Özcan, F. Er and F. Gökmen, Asian J. Chem., 23, 4177 (2011).

10. J. Ma, J. Zhang, X. Du, X. Lei and J. Li, Microchim. Acta, 168, 153 (2010).

11. X.Z. Cheng and Y. Kong, Geostand Geoanal. Res., 31, 353 (2007).

12. C.E. Säbel, J.L. Shepherd and S. Siemann, Anal. Biochem., 391, 74 (2009).

13. J.M. Joshi, P.N. Pathak, A.K. Pandey and V.K. Manchanda, Talanta, 76, 60 (2008)

14. M.A. Taher, E. Rezaeipour, D. Afzali and S.Z. Mohammadi Mobarakeh, Asian J. Chem., 17, 1463 (2005).

15. S. Antakli, N.Sarkis and A. Mahmod, Asian J. Chem., 23, 3268 (2011). 